\title{
Minimally invasive procedure for removal of infected ventriculoatrial shunts
}

\author{
Lorenzo Magrassi $^{1}$ (1) $\cdot$ Gianluca Mezzini ${ }^{1} \cdot$ Lorenzo Paolo Moramarco $^{2} \cdot$ Nicola Cionfoli $^{2} \cdot$ David Shepetowsky $^{1}$. \\ Elena Seminari ${ }^{3} \cdot$ Angela Di Matteo $^{3} \cdot$ Pietro Quaretti $^{2}$
}

Received: 10 November 2020 / Accepted: 4 December 2020

(C) The Author(s) 2020

\begin{abstract}
Background Ventriculoatrial shunts were one of the most common treatments of hydrocephalus in pediatric and adult patients up to about 40 years ago. Thereafter, due to the widespread recognition of the severe cardiac and renal complications associated with ventriculoatrial shunts, they are almost exclusively implanted when other techniques fail. However, late infection or atrial thrombi of previously implanted shunts require removal of the atrial catheter several decades after implantation. Techniques derived from management of central venous access catheters can avoid cardiothoracic surgery in such instances.

Methods We retrospectively investigated all the patients requiring removal of a VA shunt for complications treated in the last 5 years in our institution.

Results We identified two patients that were implanted 28 and 40 years earlier. Both developed endocarditis with a large atrial thrombus and were successfully treated endovascularly. The successful percutaneous removal was achieved by applying, for the first time in this setting, the endoluminal dilation technique as proposed by Hong. After ventriculoatrial shunt removal and its substitution with an external drainage, both patients where successfully weaned from the need for a shunt and their infection resolved.

Conclusion Patients carrying a ventriculoatrial shunt are now rarely seen and awareness of long-term ventriculoatrial shunt complications is decreasing. However, these complications must be recognized and treated by shunt removal. Endovascular techniques are appropriate even in the presence of overt endocarditis, atrial thrombi, and tight adherence to the endocardial wall. Moreover, weaning from shunt dependence is possible even decades after shunting.
\end{abstract}

Keywords Ventriculoatrial shunt $\cdot$ Hydrocephalus $\cdot$ Endocarditis $\cdot$ Right atrium $\cdot$ Endovascular removal

\section{Introduction}

In pediatric patients, ventriculoatrial shunts (VAS) are now rarely implanted as a first-line treatment of hydrocephalus

This article is part of the Topical Collection on Neurosurgery general

Lorenzo Magrassi

lorenzo.magrassi@unipv.it

1 Neurosurgery, Department of Clinical, Surgical, Diagnostic and Pediatric Science, University of Pavia, IRCCS San Matteo Hospital Foundation, Neurochirurgia - Fondazione IRCCS Policlinico S. Matteo, V.le Golgi 19, 27100 Pavia, Italy

2 Diagnostic Radiology, Interventional Radiology and Neuroradiology Unit, IRCCS Policlinico San Matteo Foundation, Pavia, Italy

3 Unit of Infectious and Tropical Diseases, IRCCS Policlinico San Matteo Foundation, Pavia, Italy and their use is limited to a second-line treatment when endoscopic third ventriculostomy (ETV) is not indicated or has repeatedly failed, and the peritoneum becomes an unsuitable site for shunting [10]. The main reasons for downgrading VAS to second-line treatment for hydrocephalus are its documented long-term severe cardiac and renal complications. Chronic atrial perforation [13], recurrent endocarditis [5], immune-complex glomerulonephritis [3], and tricuspid incompetence [31] have all been associated with VASs. Nevertheless, in elderly patients affected by normal pressure hydrocephalus, some have recently advocated VASs as an alternative primary treatment option to venticuloperitoneal shunts (VPSs) because, according to these authors, VASs are less likely to undergo obstruction and require shunt revision $[19,25,28]$. The apparent differences in the incidence of complications among pediatric and elderly patients may be explained by the differences in the length of follow-up of the studies in the two age groups. Follow-up in the elderly was 
limited to few years with a median ranging in those studies from 15 [19] to 42 [28] months, while in pediatric patients reported follow-ups were typically well above 10 years $[8$, 26].

Strong support for early recognition and treatment of VAS complications come from the documented reversibility of most complications after removal of the VAS especially if they result from bacterial infection [8,39]. Removal of a chronically implanted VAS catheter from the right atrium is usually not straightforward due to the frequent presence of adhesions to the endocardial structures [4] and/or the presence of a large atrial thrombus [38].

Thoracotomy is considered the method of choice for removal of a VAS when perforation of the atrial wall [13, 27] or a large thrombus is present [35], while less invasive endovascular techniques are more commonly employed for removal of a broken VAS catheter $[12,36]$.

We now report the endovascular removal of two infected VAS catheters associated with large thrombi that were implanted 28 and 40 years before and were both tightly adherent to the endovascular and endocardial wall. After removal of the catheters, both patients were progressively weaned from the intracerebral shunts, and their cardiac problems resolved.

\section{Methods and materials}

\section{Patients}

The study period was August 2015 through August 2020. All adult patients admitted at the Fondazione I.R.C.C.S. Policlinico San Matteo, Pavia with a complication linked to VAS were reviewed. Timing and approach of surgical intervention were determined on a case-by-case basis by the attending neurosurgeon and the interventional radiologist in collaboration with an infectious disease specialist. All patients signed an informed consent authorizing the use of their anonymized clinical data for retrospective analysis and clinical research.

\section{Statistics}

The working period of VAS was calculated by using the interval between VAS implantation and explantation reported in each paper and the equivalent period for our two patients. These data were analyzed according to the Kaplan-Meier model, and significant differences in time to explantation of AVS were evaluated by the log-rank test by using MedCalc software, version 18.2.1. (MedCalc Software bv, Ostend, Belgium; https://www.medcalc.org) A $p$ value $<0.05$ was considered statistically significant.

\section{Results}

In the study period encompassing 5 years, two adult patients underwent shunt removal for VAS complications. Their clinical history is summarized below:

\section{Patient no. 1}

A 59-year-old male had undergone implantation of a cystoatrial shunt for treatment of an arachnoid cyst of the right frontal lobe in 1976; no revision of the implant was ever performed. In 2014, he underwent kidney transplantation for end stage polycystic kidney disease. After transplantation, the patient presented with recurrent urosepsis. In 2016, during a mild septic episode, a floating atrial thrombus associated to the VAS catheter tip was revealed by transoesophageal echocardiography (TEE). Cerebrospinal fluid (CSF) collected by direct puncture of the valve of the VAS was sterile, and biochemical and cellular parameters were normal. During 4 weeks of antibiotic and low molecular weight heparin treatment repeated examinations by (TEE) demonstrated a progressive reduction in the size of the thrombus until it completely disappeared. One month after suspension of antibiotic therapy, the patient was readmitted to the hospital with a new mild septic episode, a methycillin resistant S. aureus was isolated in the hemocultures, and an atrial thrombus associated with the catheter tip was again visible at TEE. Considering failure of conservative treatment, we decided to remove the atrial catheter (Fig. 1a), we exposed the VAS catheter at its entrance into the venous system distal to the valve at the neck, and after cutting the catheter, its proximal stump was connected to an external ventricular drainage (EVD), the intravascular portion of the catheter was anchored to the wall of the superior vena cava where pericatheter calcifications were demonstrated by CT scan (Fig. 1b) and could not be removed by simple manual traction. Applying a refinement of the endoluminal dilation technique [33] as pioneered by Hong [18] the catheter was uneventfully removed [33] (Fig. 2). Briefly: we inserted a 4Fr valved sheath (Terumo) through the catheter exposed at the cervical level, then we advanced a 0.018 guidewire through the lumen of the catheter and navigated in the inferior vena cava, after performing several dilations of the catheter with a 6 diameter Sterling balloon catheter (Boston SC), leaving the guidewire in place, we again pulled on the atrial catheter that broke at the level of the calcifications. After removal of the segment of the catheter proximal to the calcifications, we captured from femoral approach with a $30-\mathrm{mm}$ snare (Goose Neck, Bard) both the distal end of the guidewire and the distal segment of the catheter and completely removed it through a combined endovascular access through the internal jugular and femoral veins. After the procedure, the patient was progressively weaned from the EVD which was then closed 2 weeks after surgery and completely 

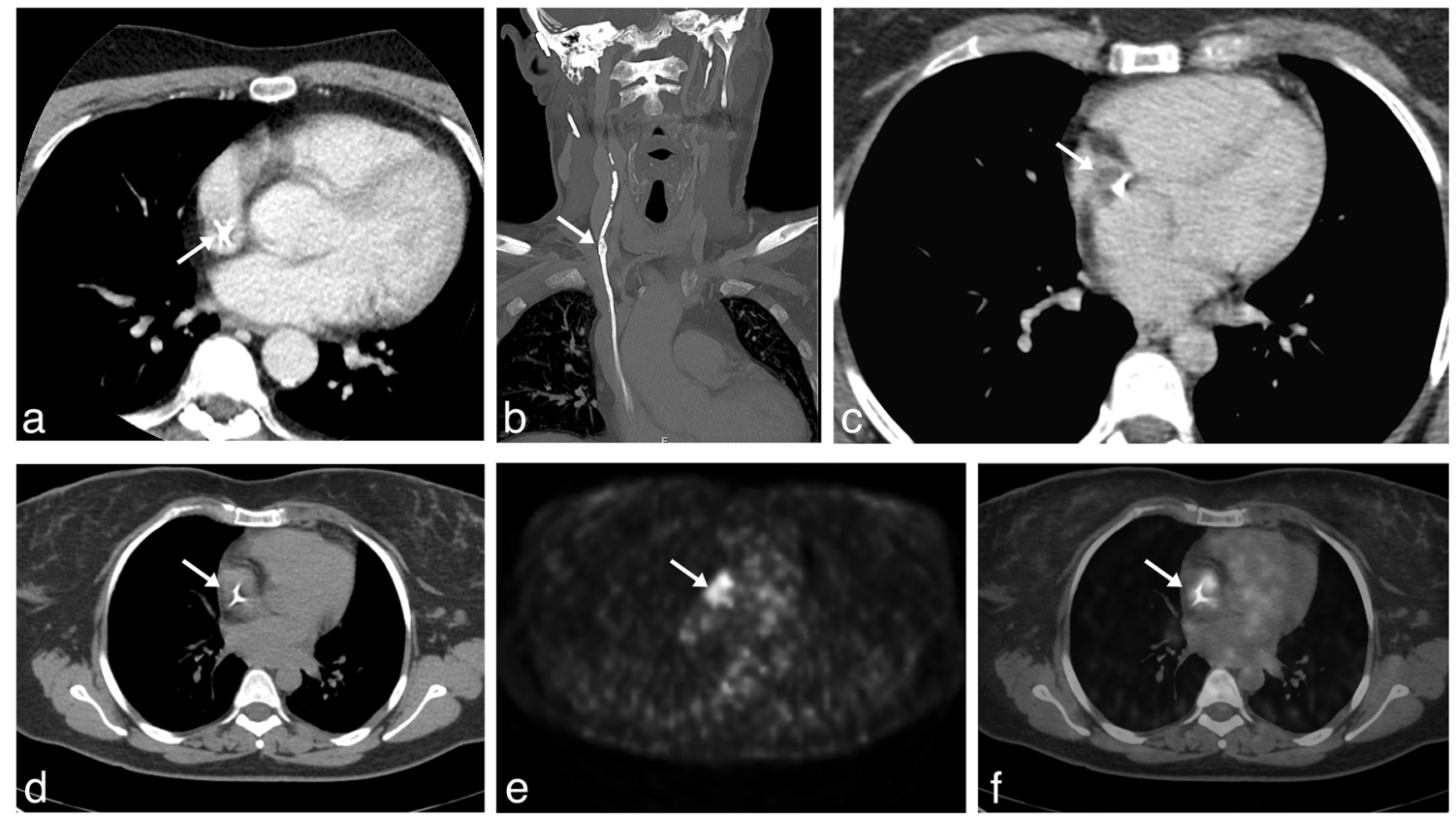

Fig. 1 Atrial condition before VAS removal. a Preoperative thoracic axial CT scan with contrast at the level of the atrium showing the VAS catheter (arrow) in patient 1. b Preoperative coronal reconstruction of the trajectory of the VAS catheter in patient 1 in the internal jugular vein, superior vena cava and atrium, radiolucency of the catheter was increased by calcium deposition in the reactive tissue surrounding the catheter, the arrow indicates the presence of macroscopic calcifications around the catheter. c Preoperative thoracic axial CT scan with contrast at the level of the atrium showing the VAS catheter in patient 2 . The arrow indicates a

removed 5 days after closure of the EVD. The neurological examination of the patient remained normal and repeated CT scans did not show any relapse of the

large atrial thrombus associated with the catheter. d Axial thoracic CT scan of patient 2, the arrow indicates the VA catheter inside the right atrium. e $\left.{ }^{18} \mathrm{~F}\right]$ fluoro-2-deoxy-d-glucose (FDG) PET scan image corresponding to thoracic CT scan in 1d, FDG accumulation (SUV 7.4) in close association with the position of the VAS-catheter (arrow) is visible. f Composite image demonstrating the colocalization of the FDG accumulation with the thrombus and reactive tissue surrounding the atrial catheter (arrow)

arachnoid cyst (Fig. 4a, b). Four years after VAS removal, the neurological condition of the patient remains stable without new septic episodes.
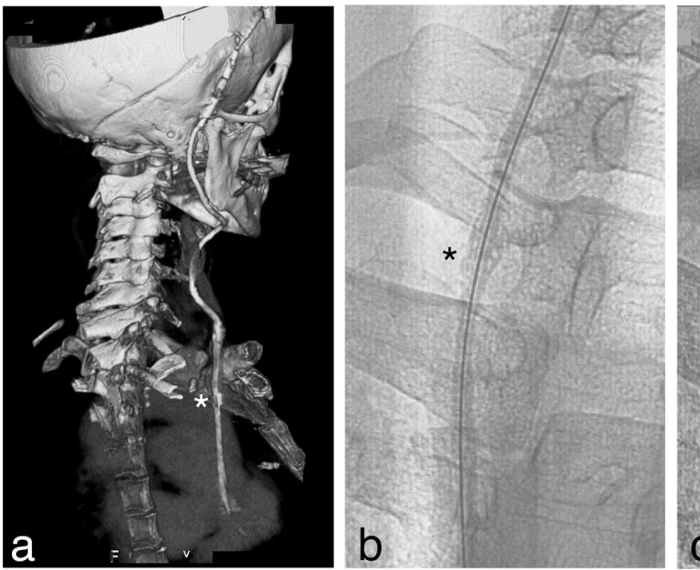

Fig. 2 Removal of VAS catheter in patient 1. a Preoperative 3D CT scan reconstruction of the VAS catheter path from the valve to the right atrium, white asterisk $\left(^{*}\right)$ marks the site of macroscopic calcifications surrounding the catheter. b Fluoroscopy antero-posterior projection, the 0,018 inch guidewire is visible inside the VAS catheter, black asterisk $\left(^{*}\right)$ marks the site of the same macroscopic calcification shown in Fig. 1a. c Fluoroscopy antero-posterior projection, the VAS catheter was dilated by a $6 \mathrm{~mm}$ diameter Sterling balloon catheter. The calcification surrounding
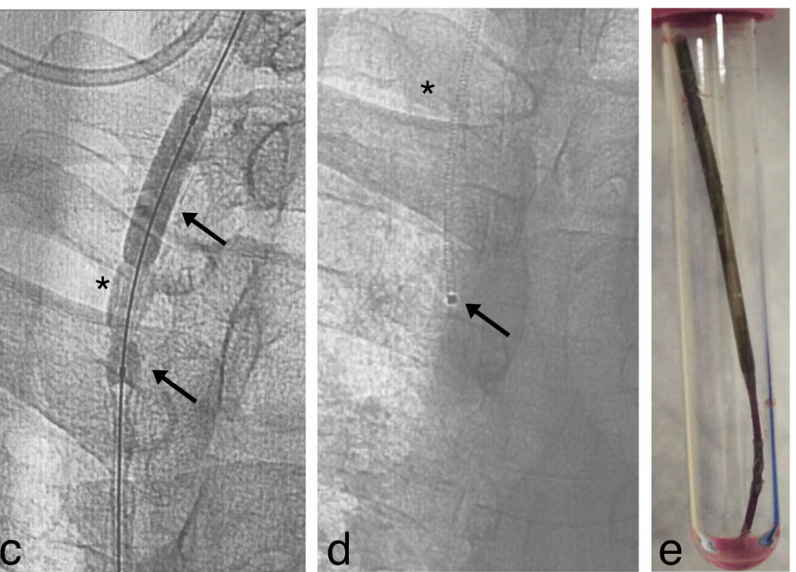

the VAS catheter partially restricts the dilation of the lumen compared to the adjacent segments (arrows), asterisk as in Fig. 1b. d Fluoroscopy antero-posterior projection, obtained after complete removal of the VAS catheter arrow points to an angiography catheter introduced after the VAS catheter was completely removed. e Picture of the distal portion of the VAS catheter immediately after extraction, the catheter is encrusted by calcified reactive tissue and partially deformed 
Fig. 4 Stability of ventricular system after VAS inactivation. CT scans obtained from patient 1 (a and b) and patient 2 (c and $\mathbf{d}$ ) before surgery (a and $\mathbf{c}$ ) and after removal of the VAS catheter from the atrium and definitive inactivation of the shunts (b and d): no appreciable increase in the diameter of the cyst and ventricles is visible. Arrows in Fig. $4 \mathrm{a}$ and $\mathrm{b}$ point to the calcified wall of the cyst
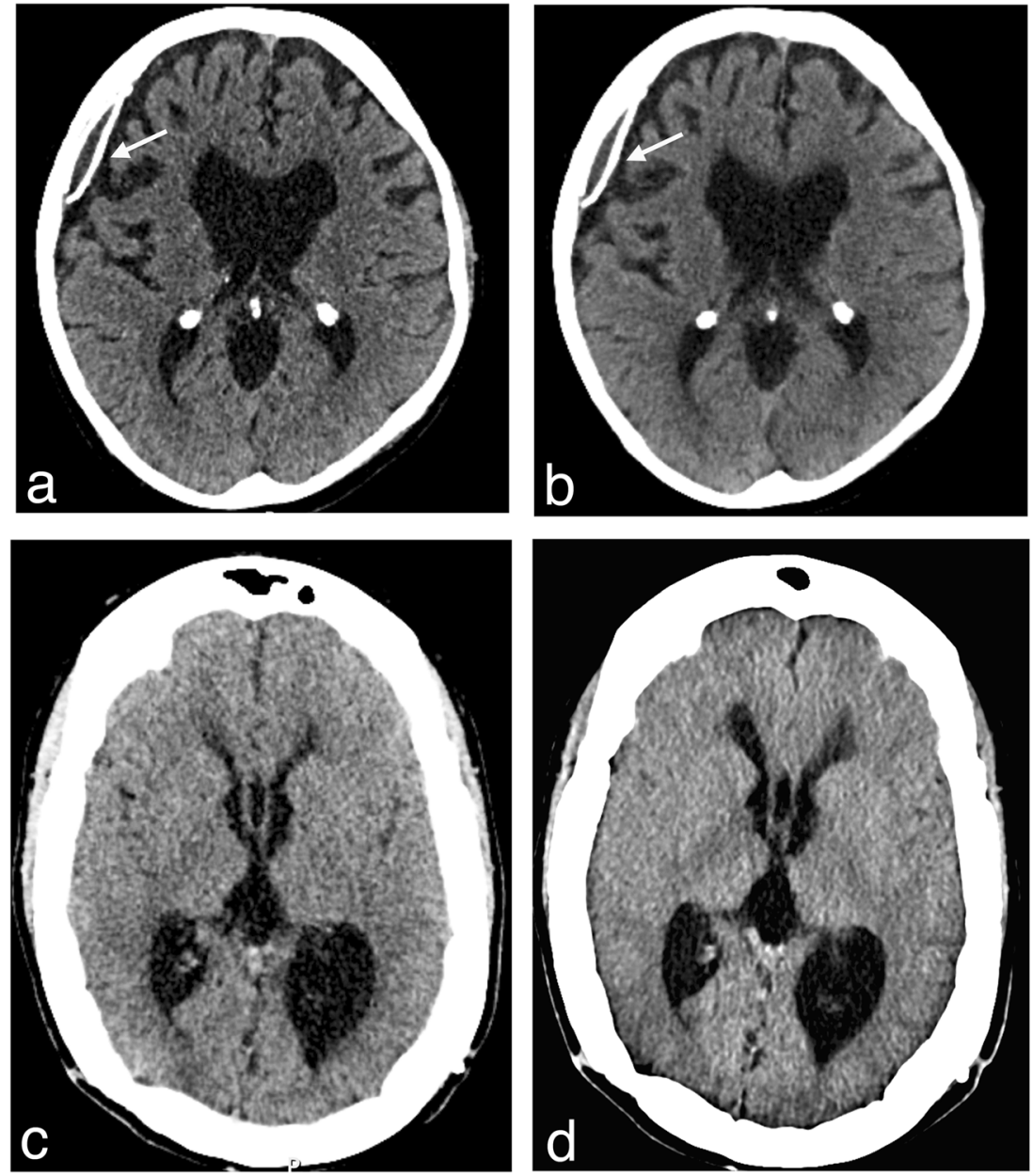

\section{Patient no. 2}

A 48-year-old female affected by myelomeningocele and hydrocephalus was operated shortly after birth and after closing the spinal defect, a VPS was implanted. In the following years, the shunt required three revisions until in 1992 the tip of the peritoneal catheter was extruded from the anus after spontaneous rectal perforation. After removal of the VPS, a VAS was implanted; the ventricular catheter and the valve of the VAS were changed in 2013 after transitory CSF infection but the atrial catheter, which was properly functioning in the absence of intracardiac vegetations or thrombi visible on TEE, was left in place.

In November 2019, after relapsing episodes of fever, she was admitted to the infectious disease unit after demonstrating a large thrombus associated with the distal tip of the VAS catheter by TEE. Multiple cultures of blood and CSF resulted sterile and an Escherichia coli was isolated from the urine. She started antibiotic therapy and low molecular weight heparin, with thrombus reduction. In March 2020, she was readmitted to the Hospital for relapsing fever; Cutibacterium acnes were isolated from multiple blood cultures, and signs of right heart failure were evident. A large thrombus around the tip of the atrial catheter was again demonstrated by TEE and thoracic angioCT (Fig. 1c). A $\left[{ }^{18} \mathrm{~F}\right]$ fluoro-2-deoxy-d-glucose (FDG) PET scan showed enhanced uptake of the tracer with a standardized uptake value (SUV) of 7.4 at the level of the thrombus (Fig. 1d, e, f). The VAS was considered as the source of the relapsing infection, and, after a collegial discussion, the removal of the whole system was planned.

Under general anesthesia (upon request of the patient), we exposed the VAS catheter at its entrance into the venous system in the neck distal to the valve and, after cutting the catheter, we connected its proximal stump to an EVD. As expected, the intravascular portion of the catheter was adherent to the vessel walls and endocardium and could not be removed by simple manual traction. Notably, the distal end of the atrial catheter appeared medialized and not free floating in the atrium on fluoroscopy. As described for patient no. 1, a 4F introducer Terumo was inserted over a 0.014 inch guidewire until the distal end of catheter was reached. Then, cautiously an over-the-wire $3.5 \times 80 \mathrm{~mm}$ balloon catheter Amphirion (Medtronic) was advanced on the guide wire and dilated two times inside the catheter (Supplementary video 1). After that, 
keeping in site the guidewire the catheter was easily retired outside (Fig. 3). Pulmonary arterial pressure was within normal limits. Femoral access previously gained for any potential rescue manoeuvre was unutilized. After the procedure, the patient was progressively weaned from the EVD which was closed 2 weeks after surgery and removed 6 days after closure. During this surgery, the ventricular catheter was ligated and left in place due to its tight adherence that made removal by manual traction hazardous. The neurological examination of the patient remains stable and repeated CT scans excluded any progressive enlargement of the ventricles (Fig. $4 \mathrm{c}, \mathrm{d}$ ).

\section{Discussion}

Patients carrying a VAS are becoming less and less frequent since this modality of treatment was relegated to a second line treatment for hydrocephalus. Nevertheless severe cardiac, renal [3,39], and hepatic [34] complications of VASs may arise decades after the initial treatment. We presented two cases of infected atrial VASs developing severe cardiac complications more than 25 years after VA shunt implantation. We found several reports describing complications of VAS in adults occurring after the postoperative period (1 month after shunt implantation). Analysis of the reported late complications requiring AVS removal together with the two described in the present work, shows that complications associated with rupture and displacement of the atrial catheter $[2,6,15,20,27$, $36,40]$ occur significantly earlier than complications not associated to rupture or displacement of the catheter $[1,4,5$, 7-9, 11, 16, 29, 30, 32, 34, 38, 39] (Fig. 5). We hypothesize that this difference reflects the common tendency of atrial catheters to become adherent to vascular and endocardial structures thus decreasing the possibility of displacement with time, but further studies are necessary to clarify this point.

In both our patients, despite tight adhesion of the shunt catheter to the superior vena cava (patient 1) or atrium (patient 2) and the presence of large atrial thrombotic vegetations, we were able to remove the catheters endovascularly without complications and with complete reversal of the associated signs and symptoms (right heart failure).

Retrieval of broken ventriculoatrial catheters trough an endovascular approach has a long history starting with open approaches requiring exposure of the involved jugular vein [37] and gradually developing into a full endovascular technique $[12,20]$. Endovascular approaches were mainly used for retrieval of broken or displaced atrial catheters. However, more complicated cases where the catheter is infected, or

Fig. 3 Removal of VAS catheter in patient 2. a Fluoroscopy antero-posterior projection, a 0.018 inch guidewire is visible inside the atrial catheter (arrow), a safety wire introduced through the femoral vein (arrowhead) was placed as a guard. b Fluoroscopy antero-posterior projection, the VAS catheter was dilated by a 3.5-mm diameter Amphirion balloon catheter. Arrow and arrowhead as in Fig. 3a. c Digital subtraction antero-posterior radiogram, the VAS catheter was distally dilated by a $3.5-\mathrm{mm}$ diameter Amphirion balloon catheter reaching the distal end of the VAS catheter. Arrow and arrowhead as in Fig. 3a. d Fluoroscopy antero-posterior projection, obtained after complete removal of the VAS catheter with the safety wire (arrowhead) and guidewire still in place (arrow). e Picture of the distal portion of the VAS catheter obtained immediately after extraction, the catheter is almost completely clean from thrombotic material that was present in vivo
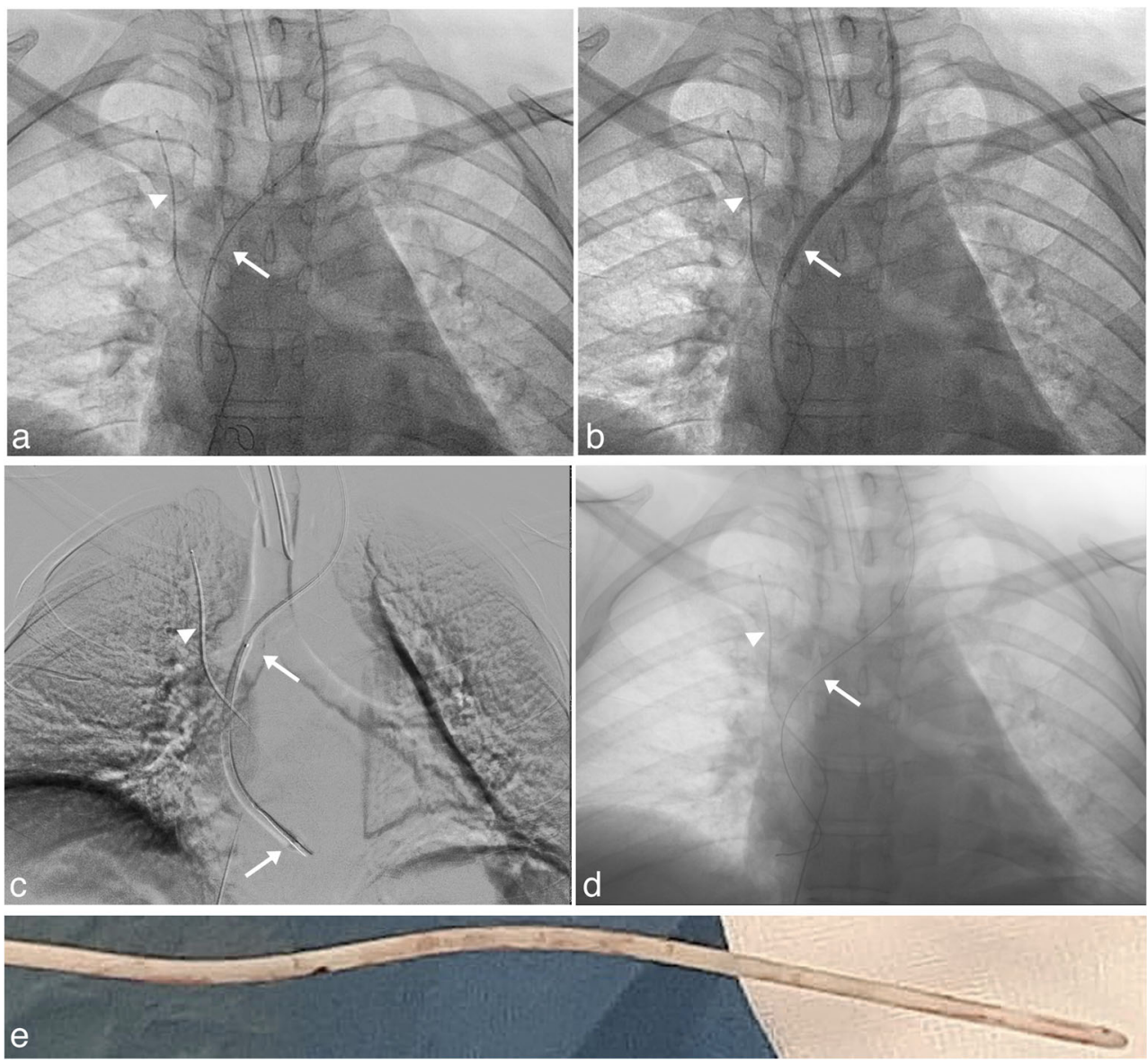


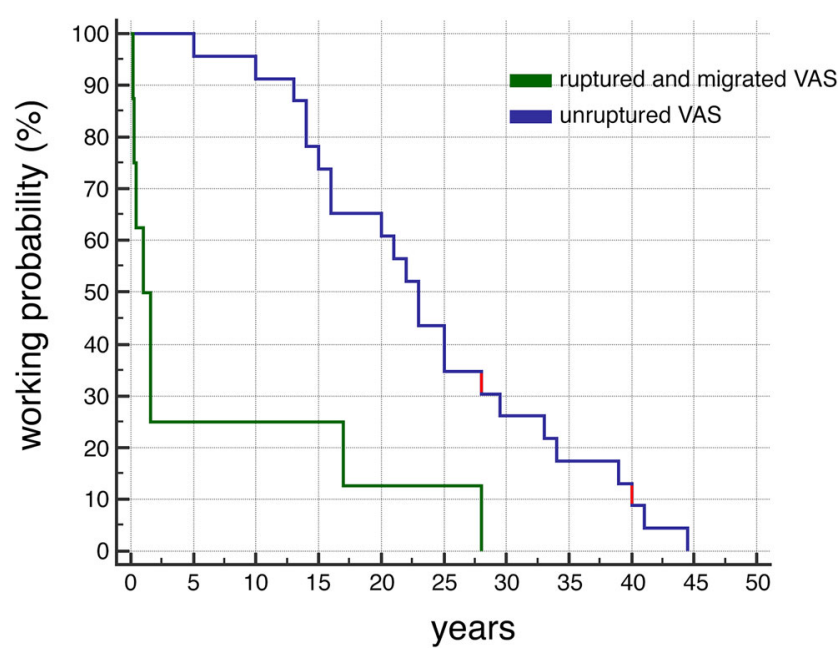

Fig. 5 Plot of the probability of working VAS with time. Data for plot were derived from the literature together with the present cases (red). Median lag before VAS removal for thrombus formation and/or infection was 23 years ( $\min 5$ years, max 44.5 years, $n=23$ patients) while median lag for rupture and or migration of the atrial catheter was 1.29 years ( $\min 0.16$ years, $\max 28$ years, $n=8$ patients)

enclosed by a large thrombus, or adherent to the atrial wall or to the leaflets of the tricuspid valve are still treated by thoracotomy $[13,16,27]$. Moreover, emergency thoracotomy is still considered mandatory after cardiac tamponade due to accumulation of CSF in the pericardium secondary to chronic perforation of the atrium by the tip of a VAS catheter which then protrudes into the pericardial space [13, 22, 27]. Finally, atrial catheters associated with tricuspid regurgitation if paucisymptomatic are sometimes left in place with strict clinical monitoring [31].

The first of our patients developed infectious endocarditis few months after kidney transplantation for end stage kidney disease due to polycystic kidney disease. Immune-complex membranoproliferative glomerulonephritis has also been described as a complication of chronic bacterial infection of VASs [3,39] that can lead to kidney failure and kidney transplantation. VAS removal is usually followed by complete regression of the glomerulonephritis [3], and it is thus mandatory whenever possible.

Another severe complication of VASs is development of pulmonary hypertension secondary to recurrent pulmonary embolization due to chronic formation of thrombi in and around the atrial catheter of the shunt $[14,30]$. The incidence of this complication in a large case series with a median interval between shunt insertion and diagnosis of 15 years was $8 \%$ (3 of 38 patients) [23] Moreover, risk of developing pulmonary hypertension following VAS increases after shunt infection $[2,7,11]$.

In both our patients before removing the catheters, we tried conservative treatment with antibiotics and heparin [9]. However, despite an initial improvement, the infection and endocardial vegetations recurred shortly after stopping the antibiotic treatment. Removal of the atrial catheter in our cases was necessary for infection eradication with immediate resolution of all endocardial thrombi. Despite tight adhesion of the catheters to endovascular structures and presence of thrombi, we were able to remove the catheters through a novel endovascular approach. We applied for the first time, to the best of our knowledge, the endovascular catheter dilation technique introduced in the last decade for removal of adherent dialytic central venous catheters to very old atrial catheters carried by our patients. As suggested by Hong, the endocatheter dilation by inflation of low-profile balloon catheters permitted to disrupt fibrous encasement around the distal VAS catheter, allowing the outside retrieval. This technique was successful despite the presence of calcifications encasing the catheter in our first patient and tight adherence to the atrial wall in the second patient. The endocatheter dilation technique [33] we adopted in our patients resulted as efficient as the laser-assisted extraction technique that has been used in the past to remove an entrapped VAS catheter [4] with the advantage of not requiring an endovascular laser apparatus that has a significant initial cost and is not widely available.

Both our patients were made shunt free despite a long story of shunt dependence and preoperative evidence that at least the proximal catheter was patent since in both patients we collected ventricular CSF by tapping the valve before removal of the VAS, and in both CSF was regularly drained by the EVD while it was progressively raised before we closed the system. One patient originally, had the shunt implanted to drain an arachnoid cyst into the atrium, leading to an initial reduction and later stabilization of the cyst. The cyst did not recur after removal of the shunt. The other patient carrying a left VAS for hydrocephalus eleven years before removal, required emergency surgery to replace the malfunctioning valve and ventricular catheter after acutely developing obvious sign of intracranial hypertension including headache, blurred vision followed by coma. Despite this, both patients have by now long surpassed their 1 month follow-up which is considered the typical period for developing clinical symptoms after failure of substituting a ventricular shunt by ETV [17]. Although, the number of patients in our series is too limited for any conclusion regarding shunt dependence, and examples of shunt dependence after almost five decades have been reported [21] we cannot help but notice that older patients with a long history of shunting are also better candidates for successful ETV [17, 24] being less shunt dependent than patients with a similar initial indication for shunting but a shorter history of shunting.

\section{Conclusion}

VASs are rarely implanted nowadays, but many patients still carry this type of device. Neurosurgeons should not forget that 
the severe complications linked to VAS may present even decades after shunt implantation. In our experience, endovascular removal of the atrial catheter through the endoluminal dilation technique seems to be safe even in the presence of large thrombi and tight adhesion to the endocardial structures. In the absence of cardiac perforation or severe pulmonary hypertension, the endovascular approach should be tried before referring the patients to the cardiac surgeon. Finally, a short period of conversion to external drainage of the shunt may be useful not only in order to monitor sterility of the CSF during antibiotic therapy but also to test whether definitive weaning from any type of shunt is possible.

Supplementary Information The online version contains supplementary material available at https://doi.org/10.1007/s00701-020-04675-1.

Authors' contribution LM designed the study and wrote the initial manuscript. All authors collected, assembled, and analyzed the data. All authors read, edited, and approved the manuscript.

Funding Open access funding provided by Università degli Studi di Pavia within the CRUI-CARE Agreement.

\section{Compliance with ethical standards}

This is a retrospective study, and all patients signed a consent for the use of their clinical data after anonymization.

Conflict of interest The authors declare that they have no conflict of interest.

Ethical approval All procedures performed in studies involving human participants were in accordance with the ethical standards of the institutional and/or national research committee and with the 1964 Helsinki declaration and its later amendments or comparable ethical standards. For this type of study, formal consent is not required

Open Access This article is licensed under a Creative Commons Attribution 4.0 International License, which permits use, sharing, adaptation, distribution and reproduction in any medium or format, as long as you give appropriate credit to the original author(s) and the source, provide a link to the Creative Commons licence, and indicate if changes were made. The images or other third party material in this article are included in the article's Creative Commons licence, unless indicated otherwise in a credit line to the material. If material is not included in the article's Creative Commons licence and your intended use is not permitted by statutory regulation or exceeds the permitted use, you will need to obtain permission directly from the copyright holder. To view a copy of this licence, visit http://creativecommons.org/licenses/by/4.0/.

\section{References}

1. Akram Q, Saravanan D, Levy R (2011) Valvuloplasty for tricuspid stenosis caused by a ventriculoatrial shunt. Catheter Cardiovasc Interv 77(5):722-725

2. Amelot A, Bouazza S, George B, Bresson D (2014) Causative role of infection in chronic non-thromboembolic pulmonary hypertension following ventriculo-atrial shunt. $\mathrm{Br} \mathrm{J}$ Neurosurg 28(4):559-561

3. Arze RS, Rashid H, Morley R, Ward MK, Kerr DN (1983) Shunt nephritis: report of two cases and review of the literature. Clin Nephrol 19(1):48-53

4. Bastian D, Fessele K, Bednarski P, Göhl K (2016) Interventional laser-assisted extraction of an infected trapped ventriculoatrial shunt based on techniques for pacemaker lead explantation. J Neurol Surg A Cent Eur Neurosurg 77(01):073-076

5. Bellamy CM, Roberts DH, Ramsdale DR (1990) Ventriculo-atrial shunt causing tricuspid endocarditis: its percutaneous removal. Int $\mathrm{J}$ Cardiol 28(2):260-262

6. Blazicek H, Oder W (2007) Recurrent fever in patient in a minimally responsive state: an unusual origin of infection. Brain Inj 21(3):339-341

7. Bonderman D, Jakowitsch J, Redwan B et al (2008) Role for staphylococci in misguided thrombus resolution of chronic thromboembolic pulmonary hypertension. Arterioscler Thromb Vasc Biol 28(4):678-684

8. Burström G, Andresen M, Bartek J, Fytagoridis A (2014) Subacute bacterial endocarditis and subsequent shunt nephritis from ventriculoatrial shunting 14 years after shunt implantation. BMJ Case Rep. https://doi.org/10.1136/bcr-2014-204655

9. Buxton N, Firth JL (2002) Heparin treatment of atrial thrombus in ventriculo-atrial shunts. Br J Neurosurg 16(1):62-63

10. Clark DJ, Chakraborty A, Roebuck DJ, Thompson DNP (2016) Ultrasound guided placement of the distal catheter in paediatric ventriculoatrial shunts-an appraisal of efficacy and complications. Childs Nerv Syst ChNS Off J Int Soc Pediatr Neurosurg 32(7): 1219-1225

11. Drucker MH, Vanek VW, Franco AA, Hanson M, Woods L (1984) Thromboembolic complications of ventriculoatrial shunts. Surg Neurol 22(5):444-448

12. Ekong CE, Gabriel YH, Lopez JF (1979) Percutaneous transfemoral retrieval of the "runaway" ventriculoatrial shunt. Can J Surg 22(5):456-457

13. El-Eshmawi A, Onakpoya U, Khadragui I (2009) Cardiac tamponade as a sequela to ventriculoatrial shunting for congenital hydrocephalus. Tex Heart Inst J 36(1):58-60

14. Favara BE, Paul RN (1967) Thromboembolism and cor pulmonale complicating ventriculovenous shunt. JAMA 199(9):668-671

15. Gibold X, Husson A, Corbain V, Vidal M, Gourdon F, Laurichesse H, Beytout J, Irthum P, Ferrier A, Lesens O (2006) Cryptococcal meningitis disclosed by visual loss in HIV negative patient with ventriculo-atrial shunting. Rev Med Interne 27(4):330-332

16. Gopal VV, Peethambaran AK (2016) Rare sequelae following ventriculoatrial shunt: Case report and review of literature. Asian J Neurosurg 11(2): 173

17. Hersh DS, Dave P, Weeks M, Hankinson TC, Karimian B, Staulcup S, Van Poppel MD, Wait SD, Vaughn BN, Klimo P (2020) Converting pediatric patients and young adults from a shunt to a third ventriculostomy: a multicenter evaluation. Neurosurgery 87(2):285-293

18. Hong JH (2011) A breakthrough technique for the removal of a hemodialysis catheter stuck in the central vein: endoluminal balloon dilatation of the stuck catheter. J Vasc Access 12(4):381-384

19. Hung AL, Vivas-Buitrago T, Adam A, Lu J, Robison J, Elder BD, Goodwin CR, Jusué-Torres I, Rigamonti D (2017) Ventriculoatrial versus ventriculoperitoneal shunt complications in idiopathic normal pressure hydrocephalus. Clin Neurol Neurosurg 157:1-6

20. James CA, McFarland DR, Wormuth CJ, Teo CM (1997) Snare retrieval of migrated ventriculoatrial shunt. Pediatr Radiol 27(4): 330-332

21. Jones HM, Hussain R, Leach P (2015) Patient dependant on ventriculo-atrial shunt after 49 years. Br J Neurosurg 29(4):587588 
22. Jorro Barón F, Casanovas A, Guaita E, Bolasell C, Rombolá V, Debaisi G (2012) Cardiac tamponade as a complication of ventriculo atrial shunt. Arch Argent Pediatr 110(1):e1-e3

23. Kluge S, Baumann HJ, Regelsberger J, Kehler U, Gliemroth J, Koziej B, Klose H, Meyer A (2010) Pulmonary hypertension after ventriculoatrial shunt implantation: clinical article. J Neurosurg 113(6):1279-1283

24. Kulkarni AV, Drake JM, Mallucci CL, Sgouros S, Roth J, Constantini S, Canadian Pediatric Neurosurgery Study Group (2009) Endoscopic third ventriculostomy in the treatment of childhood hydrocephalus. J Pediatr 155(2):254-259.e1

25. Liu A, Sankey EW, Jusué-Torres I, Patel MA, Elder BD, Goodwin CR, Hoffberger J, Lu J, Rigamonti D (2016) Clinical outcomes after ventriculoatrial shunting for idiopathic normal pressure hydrocephalus. Clin Neurol Neurosurg 143:34-38

26. Lundar T, Langmoen IA, Hovind KH (1991) Fatal cardiopulmonary complications in children treated with ventriculoatrial shunts. Childs Nerv Syst 7(4):215-217

27. Mastroianni C, Chauvet D, Ressencourt O, Kirsch M (2013) Late ventriculo-atrial shunt migration leading to pericardial cerebrospinal fluid effusion and cardiac tamponade. Interact Cardiovasc Thorac Surg 16(3):391-393

28. McGovern RA, Kelly KM, Chan AK, Morrissey NJ, McKhann GM (2014) Should ventriculoatrial shunting be the procedure of choice for normal-pressure hydrocephalus? J Neurosurg 120(6): $1458-1464$

29. Milton CA, Sanders P, Steele PM (2001) Late cardiopulmonary complication of ventriculo-atrial shunt. The Lancet 358(9293):1608

30. Pascual JM, Prakash UB (1993) Development of pulmonary hypertension after placement of a ventriculoatrial shunt. Mayo Clin Proc 68(12):1177-1182

31. Pradini-Santos L, Craven CL, Watkins LD, Toma AK (2020) Ventriculoatrial shunt catheter tip migration causing tricuspid regurgitation: case report and review of the literature. World Neurosurg 136:83-89

32. Prastaro M, Rapacciuolo A, di Pietro E, Esposito C, Esposito F, Russolillo V, Iodice R, Orefice G, Vosa C, Chiariello M (2009) Recurrent pulmonary and cerebral thromboembolism in an adult patients following incomplete removal of ventriculoatrial shunt for congenital hydrocephalus. BMJ Case Rep 2009: bcr03.2009.1645. https://doi.org/10.1136/bcr.03.2009.1645

33. Quaretti P, Galli F, Fiorina I, Moramarco LP, Spina M, Forneris G, Torresi M, Bellazzi R (2014) A refinement of Hong's technique for the removal of stuck dialysis catheters: an easy solution to a complex problem. J Vasc Access 15(3):183-188

34. Schirmer SH, Kiefer M, Kim YJ, Schneider G, Schäfers HJ, Zimmer V (2013) Secondary Budd-Chiari syndrome complicating calcified right atrial thrombosis related to ventriculoatrial shunt. Clin Res Cardiol Off J Ger Card Soc 102(2):165-168

35. Steele J, Stewart R, Komarlu R, Najm H (2018) Large superior vena cava thrombus requiring thrombectomy as a complication of ventriculo-atrial shunt. J Card Surg 33(7):397-398

36. Strohmer B, Altenberger J, Pichler M (2012) A new approach of extracting embolized venous catheters using a large-diameter steerable sheath under biplane fluoroscopy. Clin Imaging 36(5):502508

37. Tatsumi T, Howland WJ (1970) Retrieval of a ventriculoatrial shunt catheter from the heart by a venous catheterization technique: technical note. J Neurosurg 32(5):593-596

38. Tonn P, Gilsbach JM, Kreitschmann-Andermahr I, Franke A, Blindt R (2005) A rare but life-threatening complication of ventriculo-atrial shunt. Acta Neurochir (Wien) 147(12):1303-1304

39. Völker LA, Burkert K, Scholten N, Grundmann F, Kurschat C, Benzing T, Hampl J, Becker JU, Müller R-U (2019) A case report of recurrent membranoproliferative glomerulonephritis after kidney transplantation due to ventriculoatrial shunt infection. BMC Nephrol 20(1):296

40. Wu X-J, Luo C, Liu Z, Hu G-H, Chen J-X, Lu Y-C (2011) Complications following ventriculo-peritoneal and subsequent ventriculo-atrial shunting resolved by third ventriculostomy. $\mathrm{Br} \mathrm{J}$ Neurosurg 25(2):300-302

Publisher's note Springer Nature remains neutral with regard to jurisdictional claims in published maps and institutional affiliations. 